\title{
The Effect of Plyometric Training to Speed of Volleyball Athletes
}

\author{
Mansur \\ Faculty of Sport Sciences \\ Universitas Negeri Yogyakarta \\ Yoyakarta, Indonesia \\ mansur@uny.ac.id
}

\author{
Subagyo Irianto \\ Faculty of Sport Sciences \\ Universitas Negeri Yogyakarta \\ Yoyakarta, Indonesia \\ subagyo_irianto@uny.ac.id
}

\author{
Faidillah Kurniawan \\ Faculty of Sport Sciences \\ Universitas Negeri Yogyakarta \\ Yoyakarta, Indonesia \\ faidillah_fencing@uny.ac.id
}

\begin{abstract}
- the purpose of this study was to determine the effects of plyometric training (dynamic and static plyometric training) on the speed of YUSO Sleman athletes. The sample of 18 volleyball athletes divided into two group (dynamic plyometric group and static plyometric group). In addition, speed performance was assessed by a 35-meter speed run test. This study is considered an experimental research design. A paired test was used to define the effects of plyometric training (dynamic and static plyometric training) on a speed of YUSO Sleman athletes. Independent t-test was used to evaluate the different effect of dynamic and static plyometric training. The analysis data result showed that is no significant effect of dynamic plyometric training on speed $(p=0,134)$; no significant effect of statistic plyometric training on speed $(p=0,176)$, and no significantly different effect of dynamic and statistic plyometric training on speed $(p=0,214)$. The data result suggests that plyometric training did not effective to improve speed.
\end{abstract}

Keywords—plyometric, speed, volleyball atheletes

\section{INTRODUCTION}

Volleyball is a sport with complex movements. Good coordination between eyes, hands, and feet is needed during the practice of this sports. The ability of volleyball players is influenced by various factors such as 1) talent, 2) physical ability, including: (a) strength, (b) endurance, (c) speed, (d) agility, (e) flexibility, (f) coordination, (g) power, (h) stamina, 3 ) intelligence, 4) motivation [1]. The success of achieving training targets is based on several aspects including physical exercise, technique, tactics, and mental training.[2]

Physical conditions are one of the most important factors in achievement. An excellent physical condition is needed in order to achieve high performance in competitive sports. The prime physical condition should be determined by the needs of every athlete, especially for sports that demand long-term heavy performance. To reduce the risk of injury, maintain physical performance, master complex skills, accelerate recovery after exercise and increase self-confidence are some benefits obtained from the prime physical condition.

Physical conditions are a basis for developing techniques, tactics, strategies and mental development. Different studies[3], have been stated that the goal of training physical conditions is to optimize the performance of athletes and minimize the risk of injury and disease. Physical condition status can reach the optimal point if it starts training from an early age, carried out continuously throughout the year, tiered and guided by the principles of training correctly. In addition, the development of physical conditions must be planned periodically based on the stages of exercise, the status of the athlete's physical condition, the needs of each number/ class/sport, the balanced nutrition, adequate facilities and equipment, a healthy environment and the level of training of athletes. These conditions apply to all sports, including the volleyball. Therefore, the training with the aim to improve physical conditions needs to be implemented properly.

There are several types of physical training methods. Plyometric training is one type of exercise that can be used to improve physical condition. It is carried out by the current trainer, especially to sports that require the ability of the explosive muscles like the leg muscles or arm muscles [4]. It is quite popular because it can increase muscle power. Plyometric training is a form of exercise characterized by the development of maximum strength in a shortest possible time (Donald A. Chu, 1992: 1). It is considered very important to improve a person's physical condition. The effect of this type of training on power, agility, speed, and strength need to be further study.

\section{METHODS}

This research used an experimental method, with the aims to investigate the interconnected cause and effect by wearing one or more treatment conditions to one experimental group.

The sampling technique is based on purposive sampling, chosen specifically based on research objectives [6]. The population in this study were Yuso Sleman volleyball athletes. The data collection techniques used were by testing and measurement techniques. The data was taken directly through tests and measurements with speed test. Data analysis techniques applied in this study were the quantitative analysis. Paired t-test and independent t-test are used in this study.

The plyometric training program in this study used a variation and constant plyometric program. The subject warmed up for 15 minutes then directly plyometric exercise was performed for 20 minutes before technical and tactic exercise.

\section{RESUlT AND DisCUSSION}

The results of paired t-test have been showed that the constant (front) plyometric training was not significant $(0,199)$ generating an effect on speed. Plyometric variation exercises (front, back, right side left) are not significant 
(0.172) and they don't have an effect on increasing speed. The independent results of the t-test showed that there was a significant difference between the plyometric constant and the variation with a significance of (0.043).

TABLE I. THE PERCENTAGE OF LARGE-SCALE TEST

\begin{tabular}{|l|c|c|}
\hline \multicolumn{1}{|c|}{ Variables } & t & Sig \\
\hline Constant Plyometric & 1,419 & 0.199 \\
\hline Varies Plyometric & -1.549 & 0.172 \\
\hline $\begin{array}{l}\text { Constant Plyometric* } \\
\text { Varies Plyometric }\end{array}$ & $-2,93$ & 0.043 \\
\hline
\end{tabular}

Plyometric variation exercises have a better effect on increasing speed than constant plyometric. The variation and constant plyometric have not improved significantly the speed. This result was consistent with Hosseini et al [5] but was not relevant to Mokhtari P[6]. Plyometrics, also known as "jump training" or "plyos", are exercises based around having muscles exert maximum force in short intervals of time, with the goal of increasing power. This training focuses on learning to move from a muscle extension to a contraction in a rapid or "explosive" manner, for example with specialized repeated jumping. The aim of the practice of plyometric training is to develop power. It could be the reason why plyometric training does not significantly improve speed. The athletes' speed can be improved using a variation plyometric training.

\section{CONCLUSION}

The plyometric training is not considered effective in the improvement of the speed. The variation plyometric training is considered better than a constant plyometric training improving athletes speed.

\section{REFERENCES}

[1] D. Anderson, T. Tharp, C. Elsberry, A. Best, R. Barr, and B. Legg, High School Strength Training. IOWA High School Athletic Association. (515) 432. 2011.

[2] T. O. Bompa, and G. G. Haff, Periodization: Theory and Methodology of Training. Champaign, IL: Human Kinetics Publishers. 2009.

[3] T. O. Bompa, Total Training for Young Champions. United States of America: Human Kinetics. 2000.

[4] J. Lubis, Plyometric Training. 24 februari 2016. 2005.

[5] S. S. Hosseini Rostamkhany H, Panahi M, Ann Biol Res, 2011, 2, 281.

[6] P. Mokhtari Rostami R, J motion, 24, 57. 2003. 